\title{
Fecal calprotectin and transforming growth factor-b1 in the evaluation of disease activity in patients with ulcerative colitis
}

\author{
Arafat A. Kassem ${ }^{1}$, Amir A. Fikry ${ }^{2}$, Doaa Shahin ${ }^{3}$, Hosam Aldeen Salah Shabana ${ }^{1}$, \\ Sadek Mostafa ${ }^{1}$ \\ ${ }^{1}$ Department of Internal Medicine, Faculty of Medicine, Al- Azhar University, Cairo, Egypt \\ ${ }^{2}$ Department of Surgery, Faculty of Medicine, Mansoura University, Mansoura, Egypt \\ ${ }^{3}$ Department of Clinical Pathology, Faculty of Medicine, Mansoura University, Mansoura, Egypt
}

Email address:

amrikry@yahoo.com (Amir A. Fikry)

To cite this article:

Arafat A. Kassem, Amir A. Fikry, Doaa Shahin, Hosam Aldeen Salah Shabana, Sadek Mostafa. Fecal Calprotectin and Transforming Growth Factor-b1 in the Evaluation of Disease Activity in Patients with Ulcerative Colitis. Clinical Medicine Research.

Vol. 3, No. 4, 2014, pp. 96-104. doi: 10.11648/j.cmr.20140304.14

\begin{abstract}
Aims: to evaluate the correlation between endoscopic disease activity, and fecal calprotectin, transforming growth factor-B1, Clinical Activity Index, C- reactive protein, and blood leucocytes. Methods: Ninety two patients with ulcerative colitis were enrolled and scored according to the endoscopic part of the Rachmilewitz Index. Patients and controls provided fecal and blood samples for measuring calprotectin, TGF-B1, CRP, and leucocytes. Results: The values in ulcerative colitis patients $(\mathrm{n}=92)$ compared to controls $(\mathrm{n}=20)$ : calprotectin: $728.9 \pm 388.4$ versus $22.9 \pm 12.9 \mu \mathrm{g} / \mathrm{g}$, TGF-B1: $350.1 \pm 214.7$ versus $4.3 \pm 2.01 \mathrm{pg} / \mathrm{Ml}, \mathrm{CRP}: 36.9 \pm 20.3$ versus $3.5 \pm 1.9 \mathrm{~m}$ g/L, blood leucocytes: $13.8 \pm 4.5$ versus $7.3 \pm 1.8 \mathrm{~g} / \mathrm{L}$ (all $\mathrm{P}<0.001$ ). Endoscopic disease activity correlated significantly with calprotectin (Spearman's rank correlation coefficient $r=0.545)$, TGF-B1 $(r=0.531)$, Clinical Activity Index $(r=0.520)$, CRP $(r=0.481)$, and blood leucocytes $(\mathrm{r}=436)$. Calprotectin and TGF-B1 levels were significantly lower in ulcerative colitis patients with inactive disease ( endoscopic score 0 -3, calprotectin $60.5 \pm 47.8 \mu \mathrm{g} / \mathrm{g}$, TGF-B1 $39.9 \pm 35.4 \mathrm{pg} / \mathrm{Ml}, \mathrm{P}<0.001$ ), compared to patients with mild ( score $4-6$, calprotectin $460.2 \pm 240 \mu \mathrm{g} / \mathrm{g}$, TGF-B1 $172.4 \pm 88.2 \mathrm{pg} / \mathrm{Ml}, \mathrm{P}<0.001$ ), moderate ( score 7 - 9, calprotectin $797.9 \pm 239.2 \mu \mathrm{g} / \mathrm{g}$, TGF-B1 $352.6 \pm 89.9 \mathrm{pg} / \mathrm{Ml}, \mathrm{P}<0.001)$, and high disease ( score $10-12$, calprotectin $969.2 \pm 268.9 \mu \mathrm{g} / \mathrm{g}$, TGF-B1 $486.8 \pm 211.2 \mathrm{Pg} / \mathrm{Ml}, \mathrm{P}<0.001)$. The overall accuracy for detection of histopathological active disease was $96.7 \%$ for fecal calprotectin, $94.5 \%$ for TGF-B1, $90 \%$ for Endoscopic Activity Index, $87 \%$ for Clinical Activity Index, and $65 \%$ for both blood leucocytes and CRP. Conclusion: Both fecal calprotectin and TGF-B1 correlated significantly with endoscopic disease activity, clinical activity index, CRP, and blood leucocytes. Furthermore, both calprotectin and TGF-B1 were suitable markers that can differentiate endoscopically and histopathologically inactive from active disease, thus, these two biomarkers may be used for monitoring ulcerative colitis activity.
\end{abstract}

Keywords: Fecal Calprotectin, Transforming Growth Factor-B1, Ulcerative Colitis, Disease Activity, Biomarkers, Rachmilewitz Activity Index

\section{Introduction}

Ulcerative colitis (UC) is a chronic idiopathic inflammatory condition of the large bowel characterized by remission of disease activity (1). It is important to accurately evaluate intestinal mucosal inflammation in the management of these patients particularly for the assessment of therapeutic effectiveness (2). Colonoscopy and biopsy are useful in the assessment of intestinal mucosal inflammation of patients with ulcerative colitis, but these examinations can be a heavy burden to the patient (2). Several standard markers as erythrocyte sedimentation 
rate (ESR), C-reactive protein (CRP), acute phase protein e.g., albumin, and platlets are used to aid in diagnosing and monitoring the disease. However, these markers lack specificity for gastrointestinal tract inflammation (3).

Several scores exist for the assessment of endoscopic activity in ulcerative colitis. The most frequently applied ones are the Rachmilewitz Index and the Mayo Score. Both contain clinical and endoscopic items. The Rachmilewitz Score has the advantage that the clinical as well as the endoscopic part can be used separately. Furthermore, it is easy to calculate and increasingly used in clinical practice (4).

Fecal markers may be more specific for assessing intestinal disease activity. Specifically, calprotectin has been detected in stools in direct proportion to neutrophil migration through the gastrointestinal tract (12).

Calprotectin is a calcium binding S 100 family of proteins (5). It makes up about $5 \%$ of the total protein content in the neutrophil and about $60 \%$ of the cytosolic proteins(3). It is an important granulocyte cytosolic protein that is closely related to fecal excretion of 111-indium labeled leucocytes, deemed to be the gold standard for measuring intestinal inflammation(6). This kind of protein can resist metabolic degradation caused by intestinal bacteria and is relatively stable in stools for up to one week at room temperature. It can differentiate between patients with organic or non-organic intestinal disease and can be useful in detecting colorectal cancers and inflammatory disorders, and also can be useful in predicting a relapse of inflammatory bowel disease (4). When the level of these markers is low, the presence of active inflammation in the colon is unlikely (7).

Transforming growth factor-b1 (TGF-B1) belongs to a family of multifunctional polypeptides produced by lymphoid and non-lymphoid cells. It has five different isomers. TGF-B1 has confirmed its effects on cell proliferation, immunosuppression, and wound healing (8). It plays a great role as an inducer of fibrosis and myofibroblast generation and in a biological process called Epithelial-to-Mesenchymal Transition ( EMT) In colonic diseases(9). EMT is a well established biological phenomenon important in normal tissues and organ development and in the pathogenesis of diseases ( such as chronic inflammation-related fibrosis, colorectal carcinogenesis, cancer invasion, and in mucosal healing. The inhibition of EMT seems to minimize chronic inflammation related wall fibrosis in the colon (9). In inflammatory bowel disease, TGF-B1 produced and secreted from the cells in the lamina propria and the epithelium in the colon, it controls proliferation and takes part in healing and fibrosis (27).

\section{Materials and Methods}

Ninety two patients known to have active ulcerative colitis (documented clinically, endoscopically, and histologically) were enrolled in the study, including 14 patients with proctitis, 24 patients with left sided colitis, 32 patients with extensive colitis, and 22 patients with pancolitis.

They were 52 females $(56.5 \%)$ and 40 males (43.5\%). Their mean ages were $37.9( \pm 13.54)$ years. Twenty healthy controls (10 males and 10 females) with a mean age of $29.9( \pm 7.3)$ years were included with no confirmed abnormality in the upper or lower digestive tract.

A single stool sample was collected from each patient in screw capped plastic containers that avoids toilet, water artifact and simplifies laboratory sampling at the beginning of the study. The stool samples were frozen (-20) until calprotectin determination. Fecal calprotectin was quantitated using an Enzyme Linked Immunoassay (ELISA) test (Calprest, Eurospital Trieste, Italy). The results of the test samples were calculated by the standard curve and were expressed as micrograms per milliliter. According to the manufacturer, the calprotectin cut-off point as positive was $50 \mu \mathrm{g} / \mathrm{g}$ feces.

Blood samples for measurement of a full blood count, $\mathrm{CRP}$, and transforming growth factor-b1 were delivered by the patients within 3 days prior to endoscopy.

Transforming growth factor-B1 was measured in venous blood obtained after an overnight fasting. Results were expressed as the mean of the results of the sample. Five milliliter blood was taken (without using a tourniquet) on EDTA. The blood samples were immediately placed on ice. The plasma was spun for $30 \mathrm{~min}$. in $1000 \mathrm{Xg}$ and later 10 min. at $10,000 \mathrm{Xg}$ to remove platlets (which contain a large amount of TGF) to obtain the platelet poor plasma (PPP). The activation of TGF-B1 was obtained by acidification of PPP with $2.5 \mathrm{~N}$ acetic acid/ 10 urea and later $\mathrm{Ph}$ was adjusted up to $7.2-7.6$ using $2.7 \mathrm{~N} \mathrm{NaOH/1}$ MHEPES. The analysis was done by ELISA following h Human TGFB1 Immunoassay Protocol (Quantikine, R \& D Systems) method. According to the manufacturer, the TGF-B1 cut-off for counting as positive was $7.0 \mathrm{pg} / \mathrm{Ml}$.

Blood leucocytes ( normal range 4-11 g/l ), hemoglobin ( normal range for women 12- $16 \mathrm{~g} / \mathrm{dl}$, for men $13-18 \mathrm{~g} / \mathrm{dl}$ ), a sedimentation rate ( normal range for men and women up to 50 years up to $20 \mathrm{~mm} / \mathrm{h}$ and $15 \mathrm{~mm} / \mathrm{h}$; normal range for persons older than 50 years up to $30 \mathrm{~mm} / \mathrm{h}$ and up to 20 $\mathrm{mm} / \mathrm{h}$ ), as well as CRP ( upper limit of normal $<6 \mathrm{mg} / 1$ ) were determined as routine laboratory values.

Inclusion criteria were disease duration more than 3 months, complete colonoscopy including at least 6 colonic biopsies from UC- affected colon and rectum, informed consent, age from 18 - 65 years, fecal samples delivered from 3 to 1 day before colonoscopy and bowel preparation was not started until the fecal specimens were collected.

Exclusion criteria were incomplete colonoscopy, history on non-steroidal anti-inflammatory drugs and/or antibiotics during the three months preceding enrolment, colorectal cancer, crohn's disease, urinary incontinence (fear of contamination of fecal samples), inability to collect fecal samples, pregnancy, history of colorectal surgery and alcohol abuse. 
All patients underwent total colonoscopy for determining the severity of disease. Indications for colonoscopy were clinically active disease, assessment of endoscopic activity after medical treatment and dysplasia surveillance for longstanding disease.

The aim of colonoscopic examination was to confirm diagnosis, estimate disease extent, and obtain colonoscopic biopsy specimens using Pentax videoscope Ec-3840 L. Biopsies were immediately fixed in $10 \%$ neutral buffered formalin. Formalin-fixed paraffin embedded samples were prepared for histopathology and stained by hematoxylin and eosin for histological grading. The degree of inflammation was graded on a four point scale; normal (no significant inflammation), mild (elevated number of mucosal leucocytes but intact epithelium), moderate (aggregates of leucocytes with crypt abscesses and erosions but no ulceration of the epithelium), and severe (significant ulceration of the epithelium by mononuclear cell infiltrate). Histological grading was performed by a pathologist without knowledge of endoscopic or laboratory features.

Disease activity was determined through using Colitis Activity Index (CAI) by Rachmilewitz, which includes a combination of clinical and endoscopic parts (Table1). The Clinical Activity Index ( CAI ) ranges from 0-29 points, namely weekly calculation of bowel frequency, blood in stools, well-being, abdominal pain, fever, extra intestinal symptoms, erythrocyte sedimentation rate, and hemoglobin level. The Endoscopic Activity Index (EAI) ranges from 0 -12 points.

Table 1. Rachmilewitz Index for Ulcerative Colitis(11).

\begin{tabular}{|c|c|}
\hline Clinical Activity Index & Score \\
\hline \multicolumn{2}{|l|}{ 1. Number of stools weekly: } \\
\hline$<18$ & 0 \\
\hline $18-35$ & 1 \\
\hline $36-60$ & 2 \\
\hline$>60$ & 3 \\
\hline \multicolumn{2}{|c|}{ 2. Blood in stools ( based on weekly average ) : } \\
\hline None & 0 \\
\hline Little & 2 \\
\hline A lot & 4 \\
\hline \multicolumn{2}{|c|}{ 1. Investigator's global assessment of symptomatic state: } \\
\hline Good & 0 \\
\hline Average & 1 \\
\hline Poor & 2 \\
\hline Very poor & 3 \\
\hline \multicolumn{2}{|l|}{ 2. Abdominal pain / cramps } \\
\hline None & 0 \\
\hline Mild & 1 \\
\hline Moderate & 2 \\
\hline Severe & 3 \\
\hline \multicolumn{2}{|l|}{ 3. Temperature due to colitis : } \\
\hline $37-38$ & 0 \\
\hline$>38$ & 3 \\
\hline 6. Extra intestinal manifestations : & \\
\hline
\end{tabular}

\begin{tabular}{|c|c|}
\hline Clinical Activity Index & Score \\
\hline Iritis & 3 \\
\hline Erythema nodosum & 3 \\
\hline Arthritis & 3 \\
\hline \multicolumn{2}{|l|}{ 7. Laboratory findings : } \\
\hline Sedimentation rate $>50 \mathrm{~mm}$ in $1^{\text {st }} \mathrm{h}$. & 1 \\
\hline Sedimentation rate $>100 \mathrm{~mm}$ in $1^{\text {st }} \mathrm{h}$. & 2 \\
\hline Hemoglobin $<100 \mathrm{~g} / 1$ & 4 \\
\hline Endoscopic Activity Index & Score \\
\hline \multicolumn{2}{|l|}{ 1. Granulation scattering reflected light: } \\
\hline No & 0 \\
\hline Yes & 2 \\
\hline \multicolumn{2}{|l|}{ 2. Vascular pattern: } \\
\hline Normal & 0 \\
\hline Faded / disturbed & 1 \\
\hline Completely absent & 2 \\
\hline \multicolumn{2}{|l|}{ 3. Vulnerability of mucosa: } \\
\hline None & 0 \\
\hline Slightly increased ( contact bleeding ) & 2 \\
\hline Greatly increased ( spontaneous bleeding ) & 4 \\
\hline \multicolumn{2}{|c|}{ 4. Mucosal damage ( mucin, fibrin, exudates, erosions, ulcers): } \\
\hline None & 0 \\
\hline Slight & 2 \\
\hline Pronouced & 4 \\
\hline
\end{tabular}

The Clinical Index ranges from $0-29$ points, the Endoscopic Activity Index from $0-12$ points.

\section{Statistical Analysis}

Statistical analysis was performed using the statistical package SPSS version 16. The data were expressed as mean \pm SD. They were compared by t- student test for comparison between two groups and ANOVA f- test when more than two groups were compared. The association between Endoscopic disease activity, Clinical activity, fecal calprotectin, TGF-B1, CRP, and blood leucocytes was assessed by f- test. Also, Pearson's $r$ correlation and chi square test were used.

\section{Results}

Ninety two patients with ulcerative colitis were included in the study. The mean age was $37.9 \pm 13.5$ years, and $56.5 \%$ were women. The mean duration of disease to the current colonoscopy was $42.5 \pm 50.7$ months (range, $1-350$ months), none had history of surgery. Disease location in ulcerative colitis patients was as follows: proctitis $(15.2 \%)$, left sided colitis $(26.1 \%)$, extensive colitis $(34.8 \%)$, and $23.9 \%$ of patients had pancolitis.

Mean levels of fecal calprotectin and TGF-B1 were $728.9 \pm 388.4$ (range from $9-1500 \mu \mathrm{g} / \mathrm{g}$ ), $350.1 \pm 214.7$ (range from $4-800 \mathrm{pg} / \mathrm{Ml}$ ) respectively.

All patients presented with variable grades of diarrhea (mean number of motions per week was $53.7 \pm 10.25$ ), 
bloody stool based on weekly average was positive in 78 patients (A little in 50\% and A lot in 34.8\%). Abdominal cramps were detected in $85.6 \%$. Extra intestinal manifestations were detected in $56.5 \%$ (Arthritis in $26.1 \%$,
Erythema nodosum in $15.2 \%$, and Iritis in $15.2 \%$ ).

The clinical and laboratory characteristics of our patients in comparison to controls were shown in table 2.

Table 2. Clinical and laboratory characteristics of Ulcerative Colitis patients $(n=92)$ and controls $(n=20)$.

\begin{tabular}{|c|c|c|c|c|c|c|}
\hline & \multicolumn{2}{|c|}{ Ulcerative Colitis patients } & \multicolumn{2}{|l|}{ Controls } & \multirow{2}{*}{ t-test } & \multirow{2}{*}{ P.value } \\
\hline & Range & Mean \pm SD & Range & $\operatorname{Mean} \pm \mathrm{SD}$ & & \\
\hline No. of motion per week & $19-80$ & $53.7 \pm 10.2$ & $9-16$ & $13.2 \pm 6.35$ & 8.64 & 0.001 \\
\hline Temp. & $37.0-39.9$ & $38.2 \pm 10.2$ & $36.5-37.2$ & $36.9 \pm 8.7$ & 2.63 & 0.069 \\
\hline ESR & $38-150$ & $86.5 \pm 29.8$ & $4-12$ & $7.2 \pm 2.6$ & 15.62 & 0.001 \\
\hline CRP & $2-84$ & $36.9 \pm 20.3$ & $1-8$ & $3.5 \pm 1.9$ & 15.43 & 0.001 \\
\hline Blood leucocytes & $4.5-22$ & $13.8 \pm 4.5$ & $4.5-11$ & $7.3 \pm 1.8$ & 8.37 & 0.001 \\
\hline Hemoglobin & $5.2-12$ & $8.8 \pm 1.4$ & $13-17$ & $15.1 \pm 1.2$ & 6.25 & 0.009 \\
\hline Platelet count & $190-650$ & $411.2 \pm 127.8$ & $180-410$ & $279.7 \pm 74.1$ & 3.49 & 0.006 \\
\hline TGF-B1 & $4-800$ & $350.1 \pm 214.7$ & $1-7$ & \pm 2.01 & 24.9 & 0.001 \\
\hline Fecal calprotectin & $9-1500$ & $728.9 \pm 388.4$ & $10-55$ & $22.9 \pm 12.5$ & 26.2 & 0.001 \\
\hline
\end{tabular}

In our patients, the severity of disease was determined according to the Rachmilewitz Index for ulcerative colitis. The Rachmilewitz Clinical Activity Index was divided into 4 subgroups, 10 patients in remission $(9.2 \%), 16$ patients were mild $(17.4 \%), 24$ patients were moderate $(26.1 \%)$ and 42(45.7\%) patients were severe.

The Endoscopic Activity Index was divided into 4 subgroups: 8 patients in remission $(8.7 \%), 12$ patients were mild $(13.04 \%), 34$ patients were moderate $(36.9 \%)$, and 38 patients were severe $(41.3 \%)$. The base line clinical and laboratory characteristics of patients in comparison with controls are shown in table 2. The controls were healthy persons from the clinical and laboratory staff willing to provide blood and fecal samples, $50 \%$ were females, mean age $29.9 \pm 7.3$ years ( range from $20-43$ ).

The Endoscopic Activity Index ( EAI ) correlated significantly with the levels of fecal calprotectin ( Spearman's rank correlation coefficient $r=0.545$ ), TGFB1 ( $r=0.531)$, the Clinical Activity Index ( $r=0.520)$, CRP $(r=0.481)$, and blood leukocytes $(r=0.436)$. For all items $\mathrm{P}<0.001$ was found (Table 3 ) and figure (1).

Table 3. Correlation of the Endoscopic Activity Index subgroups with fecal calprotectin, TGF-B1, the Clinical Activity Index, CRP, and Blood leucocytes.

\begin{tabular}{|c|c|c|c|c|c|c|c|c|c|c|c|}
\hline \multirow{2}{*}{$\begin{array}{l}\text { Endoscopic } \\
\text { Activity } \\
\text { Index }\end{array}$} & \multirow{2}{*}{ No } & \multicolumn{2}{|c|}{ Fecal calprotectin } & \multicolumn{2}{|l|}{ TGF-B1 } & \multicolumn{2}{|c|}{ Clinical Activity Index } & \multicolumn{2}{|l|}{ CRP } & \multicolumn{2}{|c|}{ Blood leucocytes } \\
\hline & & Mean \pm SD & Range & Mean \pm SD & Range & Mean \pm SD & Range & $\begin{array}{l}\text { Mean } \pm \\
\text { SD }\end{array}$ & Range & $\begin{array}{l}\text { Mean } \pm \\
\text { SD }\end{array}$ & Range \\
\hline \multirow{2}{*}{$\begin{array}{l}\text { Inactive } \\
(0-3)\end{array}$} & \multirow{2}{*}{8} & $60.5 \pm 47.8$ & $9-140$ & $39.9 \pm 35.4$ & $4-100$ & $4.4 \pm 3.7$ & $0-13$ & $17.6 \pm 15.6$ & $2-44$ & $9.2 \pm 4.2$ & $\begin{array}{l}4.2- \\
14.8\end{array}$ \\
\hline & & $\mathrm{P}<0.001$ & & $\mathrm{P}<0.001$ & & $\mathrm{P}<0.001$ & & NS & & NS & \\
\hline \multirow{2}{*}{$\begin{array}{l}\text { Mild } \\
(4-6)\end{array}$} & & $460.2 \pm 240$ & $\begin{array}{l}15- \\
590\end{array}$ & $172.4 \pm 88.2$ & $6-300$ & $7.2 \pm 3.0$ & $4-17$ & $19.7 \pm 9.3$ & $3-35$ & $10.3 \pm 2.5$ & $\begin{array}{l}4.8- \\
15.1\end{array}$ \\
\hline & 12 & $\mathrm{P}<0.001$ & & $\mathrm{P}<0.001$ & & $\mathrm{P}<0.001$ & & $\mathrm{P}<0.001$ & & $\mathrm{P}=0.002$ & \\
\hline \multirow{2}{*}{$\begin{array}{l}\text { Moderate } \\
(7-9)\end{array}$} & \multirow{2}{*}{34} & $\begin{array}{l}797.9 \pm \\
239.2\end{array}$ & $\begin{array}{l}50- \\
1045\end{array}$ & $352.6 \pm 89.9$ & $15-430$ & $13.8 \pm 3.5$ & $4-23$ & $\begin{array}{l}41.5 \pm \\
17.4\end{array}$ & $3-74$ & $13.8 \pm 3.2$ & $\begin{array}{l}4.9- \\
19.3\end{array}$ \\
\hline & & $\mathrm{P}<0.001$ & & $\mathrm{P}<0.001$ & & $\mathrm{P}<0.001$ & & $\mathrm{P}<0.001$ & & $\mathrm{P}<0.001$ & \\
\hline $\begin{array}{l}\text { High } \\
(10-12)\end{array}$ & 38 & $\begin{array}{l}969.2 \pm \\
268.9\end{array}$ & $\begin{array}{l}266- \\
1450\end{array}$ & $486.8 \pm 211.2$ & $25-780$ & $23.6 \pm 3.5$ & $7-27$ & $\begin{array}{l}55.2 \pm \\
17.9\end{array}$ & $5-84$ & $16.2 \pm 3.9$ & $5-22$ \\
\hline
\end{tabular}




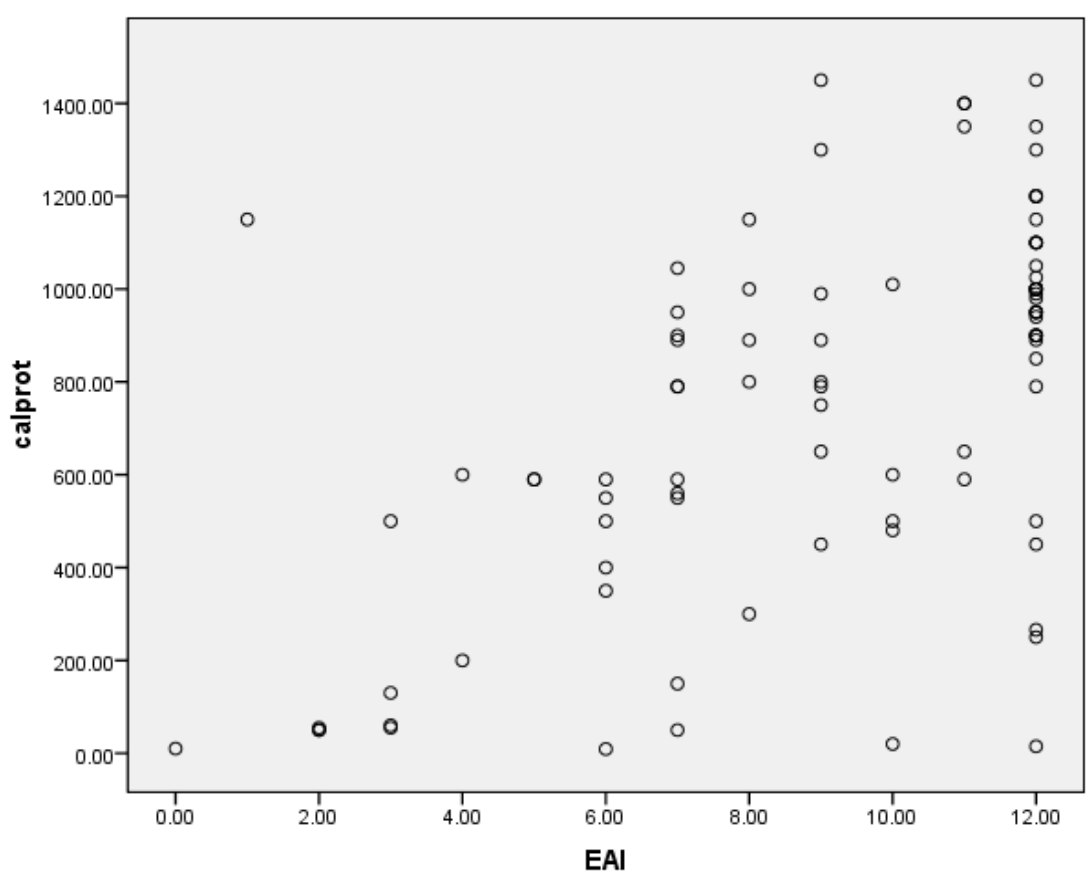

Figure 1. Scatter plot diagram illustrating the correlation of the Rachmilewitz Endoscopic Activity Index with fecal calprotectin (Spearman's correlation coefficient $=0.545$ ).

The relationship between the different subgroups of Endoscopic Activity Index with their corresponding Clinical Activity Index (CAE), fecal calprotectin, TGF-B1,
$\mathrm{CRP}$, and blood leucocytes (values given as mean $\pm \mathrm{SD}$, range, ANOVA F- test ) is shown in Table 4.

Table 4. Relationship between Endoscopic Activity Index subgroups with ESR, Platelet count, Blood leukocytes, CRP, TGF-B1, Fecal calprotectin, and Clinical Activity Index.

\begin{tabular}{|c|c|c|c|c|c|c|c|}
\hline \multicolumn{2}{|c|}{ Endoscopic Activity Index } & \multirow{2}{*}{$\begin{array}{l}\text { Inactive } \\
65-110\end{array}$} & \multirow{2}{*}{$\frac{\text { Mild }}{38-100}$} & \multirow{2}{*}{$\begin{array}{l}\text { Moderate } \\
45-145\end{array}$} & \multirow{2}{*}{$\begin{array}{l}\text { High } \\
40-150\end{array}$} & $\mathbf{F}$ & P. value \\
\hline \multirow{2}{*}{ ESR } & Range & & & & & \multirow{2}{*}{0.896} & \multirow{2}{*}{0.222} \\
\hline & Mean $\pm \mathrm{SD}$ & $83.4 \pm 22.1$ & $69.6 \pm 29.4$ & $81.4 \pm 30.1$ & $97.4 \pm 30.7$ & & \\
\hline \multirow{2}{*}{ Platelet count } & Range & $250-650$ & $190-466$ & $210-650$ & $260-620$ & \multirow{2}{*}{0.352} & \multirow{2}{*}{0.179} \\
\hline & Mean $\pm \mathrm{SD}$ & $408 \pm 148.5$ & $325.2 \pm 100$ & $394.4 \pm 129$ & $458.7 \pm 120$ & & \\
\hline \multirow{2}{*}{ Blood leucocytes } & Range & $4.2-14.8$ & $4.8-15.1$ & $4.9-19.3$ & $5-22$ & \multirow{2}{*}{3.825} & \multirow{2}{*}{0.001} \\
\hline & Mean $\pm \mathrm{SD}$ & $9.2 \pm 4.2$ & $10.3 \pm 2.5$ & $13.8 \pm 3.2$ & $16.2 \pm 3.9$ & & \\
\hline \multirow{2}{*}{ CRP } & Range & $2-44$ & $3-35$ & $3-74$ & $5-84$ & \multirow{2}{*}{3.889} & \multirow{2}{*}{0.001} \\
\hline & Mean \pm SD & $17.6 \pm 15.6$ & $19.7 \pm 9.3$ & $41.5 \pm 17.4$ & $43.9 \pm 18.9$ & & \\
\hline \multirow{2}{*}{ TGF-B1 } & Range & $4-100$ & $6-300$ & $15-430$ & $25-800$ & \multirow{2}{*}{3.886} & \multirow{2}{*}{0.001} \\
\hline & Mean \pm SD & $39.9 \pm 35.4$ & $172.4 \pm 88.2$ & $352.6 \pm 89.9$ & $486.8 \pm 211.2$ & & \\
\hline \multirow{2}{*}{ Fecal calprotectin } & Range & $9-140$ & $15-590$ & $50-1045$ & $266-1450$ & \multirow{2}{*}{6.435} & \multirow{2}{*}{0.001} \\
\hline & Mean \pm SD & $60.5 \pm 47.8$ & $420.2 \pm 240$ & $797.9 \pm 239.2$ & $969.2 \pm 268.9$ & & \\
\hline \multirow{2}{*}{ Clinical Activity Index } & Range & $0-13$ & $4-17$ & $4-23$ & $7-27$ & \multirow{2}{*}{11.075} & \multirow{2}{*}{0.001} \\
\hline & Mean $\pm \mathrm{SD}$ & $4.4 \pm 3.7$ & $7.2 \pm 3.0$ & $13.8 \pm 3.5$ & $23.6 \pm 3.5$ & & \\
\hline
\end{tabular}

When comparing the ability to discriminate between the various subgroups of the EAI, the mean fecal calprotectin in patients with remission was $60.5( \pm 47.8)$, mean fecal calprotectin in patients with mild activity was $460.2( \pm 240)$, while the mean fecal calprotectin value among patients with moderate activity was $797.9( \pm 239.2)$ and the mean fecal calprotectin value in patients with high activity was $969.2( \pm 268.9)$. These results revealed a good significant relationship between fecal calprotectin values and the different subgroups of EAI as determined by Rachmilewitz criteria $(\mathrm{P}<0.001)$.

TGF-B1 in this study can discriminate inactive endoscopic activity from mild activity $(\mathrm{P}<0,001)$, mild activity from moderate activity index $(\mathrm{P}<0.001)$, and moderate activity index from high endoscopic activity index $(\mathrm{P}<0.001)$.

The CRP and blood leucocytes in this study can't discriminate inactive endoscopic activity index from mild endoscopic activity index but can discriminate between mild activity from the moderate one $(\mathrm{p}<0.001$ and 0.002 respectively) and moderate endoscopic activity index from high endoscopic activity index $(\mathrm{P}<0.001)$.

The relationship between the different clinical activity index subgroups with their corresponding fecal calprotectin, TGF-B1, and endoscopic activity index is shown in Table (5). The mean fecal calprotectin, TGF-B1, and endoscopic 
activity index differed significantly between inactive from mild clinical activity index $(\mathrm{P}<0.001, \mathrm{p}<0.001$, and 0.015 respectively), mild from moderate clinical activity index $(\mathrm{P}$
$<0.001, \mathrm{P}<0.001$, and 0.012 respectively) and moderate from high clinical activity index (for all $\mathrm{P}<0.001$ ).

Table 5. Correlation of Clinical Activity Index with blood leukocytes, CRP, TGF-B1, Fecal calprotectin, and Endoscopic Activity Index.

\begin{tabular}{|c|c|c|c|c|c|c|c|}
\hline \multicolumn{2}{|c|}{ Clinical Activity Index } & \multirow{2}{*}{$\begin{array}{l}\text { Inactive } \\
4-14.5\end{array}$} & \multirow{2}{*}{$\frac{\text { Mild }}{4.8-15}$} & \multirow{2}{*}{$\begin{array}{l}\text { Moderate } \\
45-150\end{array}$} & \multirow{2}{*}{$\begin{array}{l}\text { High } \\
5.1-21\end{array}$} & \multirow{3}{*}{$\begin{array}{l}\mathbf{F} \\
3.455\end{array}$} & \multirow{3}{*}{$\begin{array}{l}\text { P value } \\
0.001\end{array}$} \\
\hline & Range & & & & & & \\
\hline Blood leucocytes & Mean $\pm \mathrm{SD}$ & $8.2 \pm 4.3$ & $11.2 \pm 2.2$ & $13.6 \pm 3.8$ & $17.4 \pm 3.5$ & & \\
\hline \multirow{2}{*}{ CRP } & Range & $3-40$ & $3-33$ & $3-70$ & $5-80$ & \multirow{2}{*}{6.411} & \multirow{2}{*}{0.001} \\
\hline & Mean \pm SD & $15 \pm 14.8$ & $18.2 \pm 9.1$ & $40.9 \pm 17.1$ & $43.5 \pm 18.7$ & & \\
\hline \multirow{2}{*}{ TGF-B1 } & Range & $6-90$ & $7-320$ & $15-450$ & $25-800$ & \multirow{2}{*}{3.462} & \multirow{2}{*}{0.001} \\
\hline & Mean \pm SD & $35.0 \pm 33.2$ & $176.5 \pm 93.1$ & $354.1 \pm 89.9$ & $489.7 \pm 215.1$ & & \\
\hline \multirow{2}{*}{ Fecal calprotectin } & Range & $10-130$ & $15-1150$ & $50-1450$ & $250-1500$ & \multirow{2}{*}{12.511} & \multirow{2}{*}{0.001} \\
\hline & Mean \pm SD & $54.4 \pm 45.1$ & $477.2 \pm 236.2$ & $797.9 \pm 280.9$ & $977.9 \pm 280.9$ & & \\
\hline Endoscopic & Range & $0-7$ & $1-12$ & $3-12$ & $10-12$ & \multirow{2}{*}{8.006} & \multirow{2}{*}{0.001} \\
\hline Activity Index & Mean \pm SD & $2.2 \pm 2.1$ & $6.2 \pm 2.8$ & $9.8 \pm 1.9$ & $11.9 \pm 0.3$ & & \\
\hline
\end{tabular}

From the histopathologic aspect , 21 patients ( $22.9 \%$ ) were normal, 24 were mild ( $26.1 \%$ ), 35 were moderate ( $38.0 \%)$ and 12 patients were severe ( $13.0 \%)$. There were a significant correlation between the results of histopathology with fecal calprotectin ( $\mathrm{r}=0698)$, TGF-B1 $(\mathrm{r}=0.480)$, Endoscopic Activity Index $(\mathrm{r}=0.366)$, Clinical Activity Index ( $\mathrm{r}=0.596)$, CRP $(\mathrm{r}=0.658)$, and blood leukocytes ( 0.474$)$. For all the $\mathrm{P}$ value was $<0.001$. Table 6.

Table 6. Correlation of Histopathology with Fecal calprotectin, TGF-B1, Endoscopic Activity Index, Clinical Activity Index, CRP, and blood leukocytes.

\begin{tabular}{llll}
\hline Histopathology & Spearman's Rank Correlation Coefficient( $\mathbf{r}$ ) & No. & Significance \\
Fecal calprotectin & 0.698 & 92 & 0.001 \\
TGF-B1 & 0.480 & 92 & 0.001 \\
Endoscopic Activity Index & 0.366 & 92 & 0.001 \\
Clinical Activity Index & 0.596 & 92 & 0.001 \\
CRP & 0.658 & 92 & 0.001 \\
Blood leucocytes & 0.474 & 92 & 0.001 \\
\hline
\end{tabular}

The correspondence between the results of histopathological examination and the classification based on the parameter cut-offs was analyzed for each parameter (Table ), and was expressed as the percentage of the samples that were correspondingly identified (specificity and sensitivity). The specificity was highest for fecal calprotectin and lowest for Clinical Activity Index. The specificity rates for fecal calprotectin, TGF-B1, Endoscopic
Activity Index, Clinical Activity Index, CRP, and blood leukocytes were $83 \%, 66 \%, 64 \%, 50 \%, 63 \%$, and $60 \%$ respectively. The sensitivity for fecal calprotectin was relatively high, but was relatively low for blood leucocytes. The sensitivity rates for fecal calprotectin, TGF-B1, Endoscopic Activity Index, Clinical Activity Index, CRP, and blood leucocytes were $97.5 \%, 96.5 \%, 93 \%, 89 \%$, $66 \%$, and $64.5 \%$ respectively. Table 7 .

Table 7. Sensitivity, Specificity. Positive predictive value (PPV), Negative predictive value (NPV), and the Overall Accuracy of Fecal calprotectin, TGF-B1, Clinical Activity Index, Endoscopic Activity Index, CRP, and blood leucocytes in predicting Histopathologically Active Disease.

\begin{tabular}{llllll}
\hline Marker & Cut-off & Sensitivity & Specificity & PPV & NPV \\
\hline Fecal Calprotectin & $\geq 50 \mu \mathrm{g} / \mathrm{g}$ & $97.5 \%$ & $83 \%$ & $98.8 \%$ & $71 \%$ \\
TGF-B1 & $\geq 7 \mathrm{Pg} / \mathrm{mL}$. & $96.5 \%$ & $66 \%$ & $97.6 \%$ & $57 \%$ \\
Clinical Activity Index & $\geq 5$ & $89 \%$ & $50 \%$ & $96 \%$ & $96.7 \%$ \\
Endoscopic Activity Index & $\geq 3$ & $93 \%$ & $64 \%$ & $96 \%$ & $3 \%$ \\
CRP & $\geq 6 \mathrm{mg} / \mathrm{L}$ & $66 \%$ & $63 \%$ & $78.8 \%$ & $33 \%$ \\
Blood leucocytes & $\geq 8 \mathrm{gm} / \mathrm{L}$ & $64.5 \%$ & $60 \%$ & $76.9 \%$ & $47.5 \%$ \\
\hline
\end{tabular}

\section{Discussion}

Chronic relapsing and remitting inflammation of the gastrointestinal tract is the hallmark of ulcerative colitis. One of the most prominent histological features observed in ulcerative colitis is infiltration of the neutrophils into the inflammed mucosa at an early stage of inflammation. The neutrophils are major sources of inflammatory cytokines, chemokines, proteases, and reactive oxygen derivatives, as well as a full complement of factors needed to exacerbate mucosal inflammation and tissue injury. Active inflammation in ulcerative colitis is associated with an acute phase reaction and migration of leucocytes to the gut. Thus various proteins can be measured in serum and feces (2).

Several laboratory markers have evolved in the diagnosis and follow-up of ulcerative colitis patients. These include blood leucocyte counts, ESR, and C- reactive protein. The search for fecal markers seems tempting since stools are easily accessible and more specific than serum markers that may be increased by conditions other than gut inflammation (13). 
Out of numerous neutrophil derived proteins present in stools, Calprotectin, a calcium and Zink binding protein is probably the most promising. It represents $60 \%$ of cytosolic proteins in granulocytes and therefore can be seen as directly proportional to neutrophil migration to the gastrointestinal tract (13).

Transforming growth factor-B1 plays an important role in the pathophysiology of inflammatory bowel disease (IBD). In IBD, TFG-B1 is produced and secreted 'from the cells in the lamina propria and the epithelium of the small bowel and colon. TGF-B1 controls proliferation and differentiation of intact epithelial cells, and plays a role in wound healing and increase in fibrosis during inflammation. It enhances the production of extracellular matrix by intestinal cells and fibroblast-mediated contraction of the collagen matrix, and also regulates the function of leucocytes and epithelial cells as well as their products (14). TGF-B1 may be used as a sensitive marker of ulcerative colitis activity and also can be used as a marker in differentiating inactive from active ulcerative colitis (15).

In this study, we focused on the evaluation of any relationship that might exist between the mucosal neutrophil infiltration represented by calprotectin, TGF-B1, CRP, sedimentation rate, and the ulcerative colitis disease activity represented by Rachmilewitz criteria (2).

From this study, fecal calprotectin and serum TGF-B1 correlate very closely with endoscopic disease activity, they were the only two markers that could discriminate inactive from mild, moderate, and high active disease.

Our results showed that fecal calprotectin and transforming growth factor-b1 concentrations were significantly higher in patients than controls $(\mathrm{P}<0.001)$. Also, fecal calprotectin and TGF-B1 in this study were significantly differentiate inactive from mild, moderate, and high active disease $(4,10)$. Our results correlate with Xiang et al. 2008, who found that fecal calprotectin concentrations were significantly higher in patients with active ulcerative colitis than in patients with inactive ulcerative colitis and had a better correlation with disease activity index than the CRP, ESR, or acid glycoprotein ( AGP ) concentration ( 2 ). Iman et al. 2009, Hassan et al. 2013 and Alian et al. 2009, founded that active inflammatory bowel disease patients had statistically significant elevation in fecal calprotectin than patients with inactive disease ( $3,6,4)$. Iman et al stated that fecal calprotectin was significantly elevated in inflammatory bowel disease cases in comparison to controls and is a good marker in differentiating Egyptian patients with ulcerative colitis from healthy controls (3). Hassan et al. founded that calprotectin is a suitable marker for monitoring disease activity in ulcerative colitis. The presence of calprotectin in feces is directly proportional to neutrophil migration toward the intestinal tract. Furthermore fecal calprotectin concentrations predicted the severity of colorectal inflammation, with increased concentrations strongly associated with advanced histological grades of inflammation (6). Lastly, Alian et al. found that fecal calprotectin concentrations were significantly elevated in ulcerative colitis patients than controls and can discriminate inactive from mild, moderate, and high active disease ( 4 ).

As regard to serum transforming growth factor- B1 (TGF-B1) in our results, it might be considered as a sensitive marker of ulcerative colitis activity and there was a significant elevation of TGF-B1 concentrations in ulcerative colitis patients than controls. It can also be used for evaluation of inflammatory activity in ulcerative colitis and can discriminate inactive from mild, moderate, and high disease activity.

Indeed, Irena et al. and Kilic et al. noted that in ulcerative colitis, the mean level of TGF-B1 in active disease was higher than in remission and can be used as a marker for differential diagnosis of these stages ( 15, 17 ). In a few studies TGF-B1 was measured in bowel tissue by an immunohistochemical method. Kanazawa et al. studied the expression of TGF-B1 in paraffin-embedded samples from bowel tissue and the concentration in blood, basic fibroblast growth factor (b-FGF), endothelin-1 (ET-1), and vascular endothelial growth factor (VEGF). They examined 11 patients with ulcerative colitis, 11 patients with crohn's disease, and 10 healthy controls. Expression of TGF-B1 in the endothelial cells was not found in either the ulcerative colitis or the crohn's disease group. They noted moderate or weak expression of TGF-B2 and TGF-B3 in the inflammatory cells in 5 cases of active ulcerative colitis and in 4 cases of active crohn's disease (18). Some studies were conducted in pediatric patients $(65$ children suffering from crohn's disease and 23 patients from ulcerative colitis. They found that TGF-B1 was significantly higher in patients with crohn's disease in remission than in active disease $(19,26$, and 28). In another study, Wedrychowicz et al. assessed the influence of exclusive enteral nutrition on serum concentration of TGF-B1 and vascular endothelial growth factor (VEGF) in 24 patients with crohn's disease and 15 patients with ulcerative colitis; they found increased serum TGF-B1 in ulcerative colitis patients versus the crohn's disease group and controls (20).

In this study, there was a good correlation between the Rachmilewitz Clinical Activity Index (CAI) and the endoscopic activity index (EAI) and the results correlate with the results done by Alian and his collageous. Other studies $(16,21)$, graded ulcerative colitis patients according to the Rachmilewitz Clinical Activity Index only and the Endoscopic Activity Index did not follow this score.

Focusing on the evaluation of the relationship that might exist between the mucosal neutrophil infiltration represented by fecal calprotectin, TGF-B1, CRP, blood leukocytes, and the Rachmilewitz activity indices, the present study revealed that fecal calprotectin correlated significantly with the TGF-B1, blood leucocytes, CRP, ESR, Rachmilewitz Activity Indices, but not correlated with the platelet count. Similar findings were found in various studies. Alian et al. found a good correlation between the concentrations of fecal calprotectin, Rachmilewitz Activity Indices, CRP, and blood leukocytes in ulcerative colitis 
patients (4). Also, Xiang et al. found a good correlation between fecal calprotectin, ESR, CRP, and ulcerative colitis activity index in ulcerative colitis patients (2). Kilic et al. found significant a significant correlation between TGF-B1 levels and CRP, whereas no significant correlation was established between the other parameters ( blood leucocytes, ESR, fibrinogen level, and platelet count ( 10 ).On the other hand, Irena et al. found a good correlation between TGF-B1 and the concentrations of CRP and platelet count and can be used for evaluation of inflammation activity in ulcerative colitis and to a lesser extent can also be used for evaluation of inflammatory activity in crohn's disease ( 17 ).

In our results, ulcerative colitis has a weak CRP response. Our explanation is that, in ulcerative colitis the inflammation is confined to the mucosa, and also polymorphisms in the CRP gene are responsible for interindividual differences in CRP production in humans (22). Thus, CRP doesn't seem to be an adequate biomarker for the assessment of endoscopic disease activity in ulcerative colitis

Fecal calprotectin predicts the severity of colorectal inflammation with increased concentrations strongly associated with advanced histological grades of colorectal inflammation (23). In our study, there was a significant correlation between fecal calprotectin concentrations and the results of histopathological examinations $(\mathrm{P}<0.001)$. Similar results were found in a study done by Hassan et al. who stated that fecal calprotectin concentration correlated more closely to histologic than to macroscopic colonic inflammation. This suggests that fecal calprotectin concentration may show inflammation that is not detectable macroscopically during colonoscopy.

As regard to histopathology that is considered as the gold standard test for diagnosis of ulcerative colitis, the test performance ( given by sensitivity / specificity / positive predictive value / negative predictive value and accuracy in percent ) of fecal calprotectin, TGF-B1, Endoscopic Activity Index, Clinical Activity Index, CRP, and blood leucocytes in predicting the positivity and negativity of ulcerative colitis, the fecal calprotectin with a cut-off $\geq 50$ $\mu \mathrm{g} / \mathrm{g}$ had the best overall accuracy ( $96.7 \%$ ), followed by TGF-B1 ( $94.5 \%$ ), then Endoscopic activity index ( $90 \%$ ), Clinical Activity Index ( $87 \%$ ), and lastly CRP and blood leucocytes ( for both $65 \%$ ) for detection of active disease. These results agreed with more results done by other researchers $(4,2,15,10,17$, and 25).

From the present study, we concluded that: Fecal calprotectin was the only marker that could reliably discriminate inactive from active ulcerative colitis and has the potential to replace endoscopy in disease monitoring and is considered as an objective approach to grading the mucosal disease activity in patients with ulcerative colitis. Its use as a screening test may be helpful in the selection of cases for endoscopic examination. The advantages of fecal calprotectin are the simplicity, non-invasiveness, and relatively low cost. Although inferior to calprotectin measurement, the Rachmilewitz Clinical Activity Index had good correlation with endoscopic disease activity.Transforming growth factor-B1 can be used in the early diagnosis of ulcerative colitis exacerbation. It can be used for evaluation of inflammation activity in ulcerative colitis and correlated with elevated concentrations of blood leucocytes, CRP, Clinical Activity Index, Endoscopic Activity Index, histopathology, and fecal calprotectin. Thus, TGF-B1 can be used as a marker for differentiating active ulcerative colitis patients and those in remission.Further studies are needed for determining the value of fecal calprotectin and TGF-B1 in other organic diseases, their guidance for choosing the best modality of treatment and their use as biomarkers of remission and success of management. Nevertheless, more studies with larger patient groups are necessary.

\section{References}

[1] Langhorst J, ELsenbruch S, Muller T. Comparison of 4 neutrophil-derived proteins in feces as indicators of disease activity in ulcerative colitis. Inflamm Bowel Dis. 2005; 11: $1085-1091$.

[2] Xiang JY, Ouyang Q, Li GD, Xiao NP. Clinical value of fecal calprotectin in determining disease activity of ulcerative colitis. World J Gastroenterol. 2008; 14 (1): 53 57.

[3] Iman H, Mona N, Sahar T. Preliminary evaluation of the role of fecal calprotectin in the diagnosis of ulcerative colitis among Egyptian patients. Med. J. Cairo Univ. 2009; 77 (3): $95-102$.

[4] Alain MS, Christoph B, Alex S, Michael T, Pietro R, Frank S. Ulcerative Colitis: Correlation of the Rachmilewitz Endoscopic Activity Index with Fecal Calprotectin, Clinical Activity Index, C- reactive protein, and blood leukocytes. Inflamm Bowel Dis. 2009; 15: 1851 - 1858.

[5] De Jong NSH, Leach ST, Day AS. Fecal S100 A12: A novel Non-invasive marker in children with Crohn's disease. Inflamm Bowel Dis. 12 (7): 566 - 572, 2006.

[6] Hassan N, Tarang T, Iradj M, Farshad N, Hafez F,Vahid H, Seyed MY. Calprotectin: a promising non-invasive tool for ulcerative colitis monitoring. Life Science Journal 2013; 10 (3): $1356-1360$.

[7] Aomatsu T, Yoden A, Matsumotol K. Fecal calprotectin is a useful marker for disease activity in pediatric patients with inflammatory bowel disease. Digestive Diseases and Sciences, Vol.56, 8, PP. 2372- 2377, 2011.

[8] Z. Mesut YK, Selime A, Yasemin O, Isilay N, Basak C, Aysel U. Plasma transforming growth factor- B1 level in inflammatory bowel disease. Turk J Gastroenterol 2009; 20 (3): $165-170$.

[9] Sipos F, Galambo O. Epithelial and Mesenchymal to epithelial transitions in the colon. World J. Gastroenterol., 212 - 18: $601-608$

[10] Kilic ZM, Ayaz S, Ozin Y, Nadir I, Cakal B, Ulker A. Plasma transforming growth factor-B1 level in inflammatory bowel disease. Turk J. Gastroenterol. 2009; 20: $165-170$. 
[11] Rachmilewitz D. Coated mesalazine (5-aminosalicylic acid) versus sulphasalazine in the treatment of active ulcerative colitis; a randomized trial. Br Med j. 1989; 298: 82 - 86 .

[12] Silberer H, Kuppers B, Mickisch O. Fecal leukocyte proteins in inflammatory bowel disease and irritable bowel syndrome. Clin Lab 2005, 51: 117 - 26.

[13] Vermiere S, Van Assche G, Rutgeerts P. Laboratory markers in inflammatory bowel disease: useful, magic, or unnecessary toys? Gut, 55: 426-431, 2006.

[14] Gisbert JP, Gonzalez LY, Mate J. Role of biological markers in inflammatory bowel disease. Gastroenterol Hepatol 2007; 30: $117-129$.

[15] Sheta SY, Salem MI, Ismail AW, Hafez MA. Value of fecal calprotectin as a non-invasive marker differentiating organic from functional bowel diseases. Clinical and histopathological study. Z.U.M.J 19 (4): 524 - 529. 2010.

[16] Langhorst J. Non-invasive markers in the assessment of intestinal inflammation in inflammatory bowel diseases: performance of fecal lactoferrin, calprotectin, and PMNelastase, CRP, and Clinical indices. Am. J. Gastroenterol. 103 (1): $162-9.2008$

[17] Irena CM, Iga WT, Malgorzata S, Danuta F, Konrad J, Dorota C, Tomasz M. TGF-B1 and granulocyte elastase in the evaluation of activity of inflammatory bowel disease. A pilot study. Postepy Hig Med Dosw (Online), 2014; 68: 66 72.

[18] Kanazawa S, Tsunoda T, Onuma E, Majami T, Kagiyama M, Kikuchi K. VEGF, basic- FGF, and TGF-B1 in crohn's disease and ulcerative colitis: a novel mechanism of chronic intestinal inflammation. Am. j. Gastroenterol; 2001; 96: 822 -828 .

[19] Kader HA, Tchernev VT, Satyara JE, Lejnine S, Kotler G, Kings-more SF, Patel DD. Protein microarray analysis of disease activity in pediatric inflammatory bowel disease demonstrates elevated serum PLGF, IL-7, TGF-B1, and IL12P40 levels in crohn's disease and ulcerative colitis patients in remission versus active disease. Am. J. Gastroenterol. 2005; 100: 414 - 423.

[20] Wedrychowicz A, Kowalska-Duplaga K, Jedynak-Wasowicz U, Pieczarkowicz S, Sladek M, Tomasik P, Fyderek K. Serum concentration of VEGF, and TGF-B1 during exclusive enteral nutrition in inflammatory bowel disease. $\mathrm{J}$ Pediat. Gastroenterol. Nutr. 2011; 53: 150 - 155.

[21] Canani RB, Terrin G, Rapacciuolo L. Fecal calprotectin as a reliable non-invasive marker to assess the severity of mucosal inflammation in children with inflammatory bowel disease. Dig. Liver Dis.2008; 40: 547 - 553.

[22] Carlson CS, Aldred SF, Lee PK. Polymorphisms within the C-reactive protein promoter region is associated with plasma CRP levels. Am J Hum Genet. 2005; 77: 64 - 77.

[23] Limburg PJ, Ahlquist DA, Sandborn WJ. Fecal calprotectin levels predict colorectal inflammation among patients with chronic diarrhea referred for colonoscopy. Am J Gastroenterol. 2000; 95: 2831 - 2837.

[24] Tibble JA, Teahon K, Thjodleifsson B. A simple method for assessing intestinal inflammation in crohn's disease. Gut 2000; 47: $506-513$.

[25] Hesham EDS, Ahmed AM, Manal MEA, Engy VE, Sherif SS, Ahmed SAS. The diagnostic value of fecal calprotectin in differentiating inflammatory bowel disease from irritable bowel syndrome. Report and Opinion 2011; 3 (1): 1 - 8 .

[26] Belei O, Sinedria I, Illie R, Daescu C, Tamara M, Militaru A, Brad G. Correlation of fecal calprotectin with clinical and endoscopic scores in inflammatory bowel disease in children . J Pedia Trului. 2011 Vol.XIV, 55 - 56.

[27] Victoria RS, Ian P, Christos P, Ann CW. TGF-B1 signaling, connecting aberrant inflammation and colorectal tumorigenesis. Curr. Pharmaceutical Design, 2012; 18: 1 15.

[28] Kolho KL, and Turner D. Fecal calprotectin and clinical disease activity in pediatric ulcerative colitis. ISRN Gastroenterology 2013; 179024: 1 - 5 . 